\title{
Helicobacter pylori prevalence in healthy Mexican children: comparison between two non-invasive methods
}

\author{
Verónica I. Martínez-Santos ${ }^{1}$, Manuel Hernández Catalán ${ }^{2}$, Luis Octavio Ojeda Salazar ${ }^{2}$, Octavio Andrei Orozco \\ Gómez $^{2}$, Sandra Ines Lorenzo ${ }^{2}$, Rayver Santos Gómez ${ }^{3}$, Norma S Romero-Castro ${ }^{4}$, Roxana Reyes Ríos ${ }^{5}$, Dinorah \\ Nashely Martinez Carrillo ${ }^{2}$, Gloria Fernández-Tilapa ${ }^{\text {Corresp. } 2}$ \\ ${ }^{1}$ Cátedras CONACyT-Universidad Autónoma de Guerrero, Chilpancingo, Guerrero, México \\ ${ }^{2}$ Laboratorio de Investigación Clínica, Facultad de Ciencias Químico-Biológicas, Universidad Autónoma de Guerrero, Chilpancingo, Guerrero, Mexico \\ 3 Ih Max Gabinete de Diagnóstico, Universidad de Valle de Guerrero, Chilpancingo, Guerrero, Mexico \\ 4 Escuela Superior de Odontología, Universidad Autónoma de Guerrero, Acapulco, Guerrero, Mexico \\ 5 Escuela Superior de Ciencias Naturales, Universidad Autónoma de Guerrero, Chilpancingo, Guerrero, Mexico \\ Corresponding Author: Gloria Fernández-Tilapa \\ Email address: gfernandezt@uagro.mx
}

Background. Helicobacter pylori detection in asymptomatic children with suspected infection or with symptoms that suggest gastric pathology is problematic, since most of the methods depend on the endoscopic study, an invasive and expensive method. Noninvasive methods can be a feasible alternative but must be validated. The purpose of this study was to evaluate the concordance between $H$. pylori DNA detection in saliva and dental plaque by PCR, with antigen detection in stool by immunochromatography, among asymptomatic children in the state of Guerrero, Mexico. Methods. Dental plaque, saliva, and stool samples were obtained from 171 children between 6 and 12 years old. $H$. pylori detection in saliva and dental plaque was performed by PCR using specific primers for the 16S rRNA gene, while the detection in stool samples was performed by immunochromatography using the CerTest kit. Results. We found an overall $H$. pylori prevalence of $59.6 \%$ (102/171). Of the $H$. pylori positive children $18 \%(20 / 111)$ were positive in saliva samples, $28.1 \%(34 / 121)$ in dental plaque samples, and $50.4 \%(71 / 141)$ in stool samples. A higher prevalence was found in girls $(64.7 \%, p=0.002)$. Although some of the children declared some dyspeptic symptoms, these were no related to $H$. pylori. In conclusion, we found a high prevalence of $H$. pylori in asymptomatic children and the highest proportion was detected by stool antigen test, which was the most feasible method to detect $H$. pylori infection. 
1 Helicobacter pylori prevalence in healthy Mexican children: comparison between two non2 invasive methods

3

4 Verónica I. Martínez-Santos ${ }^{1}$, Manuel Hernández-Catalán ${ }^{2}$, Luis O. Ojeda-Salazar ${ }^{2}$, Octavio A.

5 Orozco-Gómez ${ }^{2}$, Sandra I. Lorenzo-Nazario ${ }^{2}$, Rayver Santos-Gómez ${ }^{3}$, Samanta Romero-Castro ${ }^{4}$,

6 Roxana Reyes-Ríos ${ }^{5}$, Dinorah N. Martínez-Carrillo², Gloria Fernández-Tilapa ${ }^{2}$.

$8{ }^{1}$ Cátedras CONACyT, Facultad de Ciencias Químico-Biológicas, Universidad Autónoma de

9 Guerrero, Chilpancingo, Guerrero, México.

$10{ }^{2}$ Laboratorio de Investigación Clínica, Facultad de Ciencias Químico-Biológicas, Universidad

11 Autónoma de Guerrero, Chilpancingo, Guerrero, México.

$12{ }^{3}$ Ih Max Gabinete de Diagnóstico, Universidad del Valle de Guerrero, Chilpancingo, Guerrero, 13 México.

$14{ }^{4}$ Escuela Superior de Odontología, Universidad Autónoma de Guerrero, Acapulco, Guerrero, 15 México.

$16{ }^{5}$ Escuela Superior de Ciencias Naturales, Universidad Autónoma de Guerrero, Chilpancingo, 17 Guerrero, México.

Corresponding Author:

Av. Lázaro Cárdenas s/n, C.U. Sur, Col. Haciendita. C.P. 39090. Chilpancingo, Guerrero, México.

Email address: gfernandezt@uagro.mx

24

25

26

27

\section{Abstract}

Background. Helicobacter pylori detection in asymptomatic children with suspected infection or with symptoms that suggest gastric pathology is problematic, since most of the methods depend on the endoscopic study, an invasive and expensive method. Non-invasive methods can be a feasible alternative but must be validated. The purpose of this study was to evaluate the concordance between $H$. pylori DNA detection in saliva and dental plaque by PCR, with antigen detection in stool by immunochromatography, among asymptomatic children in the state of Guerrero, Mexico.

Methods. Dental plaque, saliva, and stool samples were obtained from 171 children between 6 and 12 years old. H. pylori detection in saliva and dental plaque was performed by PCR using specific primers for the $16 \mathrm{~S}$ rRNA gene, while the detection in stool samples was performed by immunochromatography using the CerTest kit.

Results. We found an overall $H$. pylori prevalence of 59.6\% (102/171). Of the $H$. pylori positive children $18 \%(20 / 111)$ were positive in saliva samples, $28.1 \%(34 / 121)$ in dental plaque samples, 
and 50.4\% (71/141) in stool samples. A higher prevalence was found in girls $(64.7 \%, p=0.002)$. Although some of the children declared some dyspeptic symptoms, these were not related to $H$. pylori. In conclusion, we found a high prevalence of $H$. pylori in asymptomatic children and the highest proportion was detected by stool antigen test, which was the most feasible method to detect $H$. pylori infection.

\section{Introduction}

H. pylori is a spiral-shaped Gram-negative bacterium that colonizes the gastric mucosa in humans. A long-lasting infection with this bacterium can cause chronic gastritis, peptic ulcer, and gastric cancer (Peek and Crabtree, 2006). This bacterium can be acquired in childhood, usually before the first ten years of life, during which it can cause a transitory infection and be cleared spontaneously (Malaty et al., 2002; Duque et al., 2012). If not cleared, H. pylori can cause gastric disorders, like peptic ulceration, abdominal pain without peptic ulceration, gastroesophageal reflux disease, and recurrent abdominal pain; as well as extra-gastric issues, like low growth rate, iron deficiency, and iron deficiency anemia (Campbell and Thomas, 2005; Rajindrajith et al., 2009). However, an overwhelming majority of infected children are asymptomatic (Jones et al., 2017). Children can acquire this bacterium from person to person, through the oral-oral or fecal-oral route; although it could also be acquired through contaminated food and water, as well as infected animals (Khalifa et al., 2010). The risk factors that influence the prevalence of $H$. pylori infection include low socioeconomic level, poor hygiene conditions, overcrowding, family history of parental gastric disease, and conditions that favor the person-toperson contact (Hasosah et al., 2015).

The frequency of $H$. pylori in Mexican children has decreased in recent years, while in 1998 the frequency of infection was found to be 50\% (Torres et al., 1998), in 2012 it was 38\% (Duque et al., 2012). However, the diagnosis of $H$. pylori infection in children is difficult to make, given that symptoms such as abdominal pain, nausea, vomiting, and occasionally diarrhea are unspecific (Bosques-Padilla et al., 2018).

Diagnostic tests to detect $H$. pylori are classified as invasive and non-invasive, depending on whether they require a gastric tissue sample obtained by endoscopy or not, respectively. Invasive tests include culture, PCR from biopsies, histopathology, and rapid urease test; while noninvasive tests include $H$. pylori antigens detection in the stool (stool antigen test, SAT), detection of antibodies anti-H. pylori in serum, PCR from oral samples, and urea breath test (Guarner et al., 2010). Of these, endoscopy and histological examination of gastric biopsies remain the gold standard for diagnosis (Campbell and Thomas, 2005). Since gastric malignancy is uncommon in children, the use of non-invasive tests to diagnose $H$. pylori gastric infection is highly preferred. Due to the potential oral transmission of $H$. pylori among children and adults, detection of the bacterium in oral cavity samples has been proposed as a diagnostic test, even though it is still not clear whether the oral cavity is another niche for the bacteria, or it is only an entry pathway (Al Sayed et al., 2014). The aim this work was to evaluate the concordance between $H$. pylori DNA 
detection in saliva and dental plaque samples by PCR, with antigen detection in stool by immunochromatography, among asymptomatic children in the state of Guerrero, Mexico.

\section{Materials \& Methods}

\section{Population}

One hundred and seventy-one children between 6 and 12 years old were invited to participate in the study. The parents were informed about the importance of early detection of $H$. pylori, those who agreed to participate signed informed written consent and were asked for a stool sample of their child. In addition, a poll was applied in order to obtain information about the children's living conditions and oral hygiene. Teacher Nanci Aneli Cabañas Villanueva, principal of the elementary school "Esc. Prim. Daniel Delgadillo C.C.T 12DPR1692 J", allowed us to contact the students enrolled in the study and their parents. The project was approved by the Bioethics Committee of the Research Directorate of the Autonomous University of Guerrero (CB004/2K20).

\section{Samples}

Before obtaining dental plaque, 1-2 $\mathrm{mL}$ saliva samples were obtained by the passive drool method. The samples were collected in sterile propylene tubes containing extraction solution (Tris $10 \mathrm{mM} \mathrm{pH} \mathrm{8,} \mathrm{EDTA} 20 \mathrm{mM} \mathrm{pH} \mathrm{8,} \mathrm{SDS} \mathrm{0.5 \% ).} \mathrm{Supragingival} \mathrm{dental} \mathrm{plaque} \mathrm{samples} \mathrm{were}$ collected by a trained odontologist using sterile Gracey curettes (Hu-Friedy, USA), and placed in microcentrifuge tubes containing $750 \mu \mathrm{L}$ of extraction solution. All samples were kept in ice while transported and then frozen at $-20^{\circ} \mathrm{C}$ until DNA extraction. Stool samples were collected by the parents in sterile containers. The samples were kept in ice until frozen.

\section{DNA extraction from dental plaque and saliva samples}

Ten microliters of proteinase $\mathrm{K}(10 \mathrm{mg} / \mathrm{mL})$ were added to the dental plaque and saliva samples previously dissolved in extraction solution. The samples were incubated at $65^{\circ} \mathrm{C}$ for $12 \mathrm{~h}$ and the total DNA was obtained by the phenol:chloroform:isoamyl alcohol method. Then it was precipitated with ethanol and the pellet was resuspended in $30 \mu \mathrm{L}$ of deionized water.

\section{H. pylori detection by PCR}

H. pylori DNA in dental plaque and saliva samples was detected by standard PCR using primers HP16-219 (5'-GCTAAGAGATCAGCCTATGTCC-3') and HPGR16SR (5'CAATCAGCGTCAGTAATGTTC-3') (Chang et al., 2006), which amplify a 522 bp fragment of the $16 \mathrm{~S}$ rRNA gene. The reaction mix was performed in a $15 \mu \mathrm{L}$ final volume, containing 2.5 $\mathrm{mM} \mathrm{MgCl} 2,0.25 \mathrm{mM}$ dNTP's, 5 pmol of each primer, $1 \mathrm{U}$ of Taq Platinum DNA polymerase (Invitrogen, Carlsbad, CA, USA), $1 \mathrm{x}$ buffer, and $150 \mathrm{ng}$ of DNA. Amplification conditions were: 1 cycle at $94^{\circ} \mathrm{C}$ for $5 \mathrm{~min} ; 40$ cycles at $94^{\circ} \mathrm{C}$ for $30 \mathrm{~s}, 55^{\circ} \mathrm{C}$ for $30 \mathrm{~s}$, and $72^{\circ} \mathrm{C}$ for $1 \mathrm{~min}$; and 1 cycle at $72^{\circ} \mathrm{C}$ for $7 \mathrm{~min}$. PCR products were subjected to $2.5 \%$ agarose gel electrophoresis, stained with ethidium bromide, and visualized with ultraviolet light (UV). Reactions without 
112 DNA were included as negative controls and reactions with DNA from $H$. pylori strain 26695

113

114

115

116

117

118

119

120

121

122

123

124

125

126

127

128

129

130

131

132

133

134

135

136

137

138

139

140

141

142

143

144

145

146

147

were included as positive controls. DNA integrity was verified adding primers Sense (5'CATTTGTCAGGTTCTTGATC-3') and Antisense (5'-GAAGTTTAGTCTTCCCACTT-3'), which are specific for the promoter region of the human IL-1B gene and amplified a $305 \mathrm{bp}$ fragment (Roman-Roman et al., 2017) (Fig. 1). Only IL-1B-positive samples were included in the study.

\section{H. pylori antigens detection in feces}

Detection of $H$. pylori antigens in stools samples was performed using the immunochromatographic one-step test CERTEST H. pylori (CerTest, Biotec, S.L, Zaragoza, España) following manufacturer's instructions. This test is a colored chromatographic immunoassay for the qualitative detection of $H$. pylori in stool samples. The strip consists of a nitrocellulose membrane pre-coated with mouse monoclonal antibodies against $H$. pylori on the test line, and with rabbit polyclonal antibodies against a specific protein, on the control line. The sample absorbent pad is sprayed with a solution of mouse monoclonal antibodies anti-H. pylori conjugated to red polystyrene latex, and a control solution of a specific binding protein conjugated to green polystyrene latex, forming colored conjugate complexes. A green line appearing in the control line in the results window is an internal control, which confirms sufficient specimen volume and correct procedural technique. The presence of this green line serves as 1) verification that sufficient volume is added, 2) that proper flow is obtained and 3) an internal control for the reagents.

The results were considered negative when only the green line appeared in the results window; positive when in addition to the green control line, a red line also appeared in the site marked with the letter $\mathrm{T}$ (test line); and invalid when the green line was completely absent, regardless of the appearance or not of the red line (Fig. 2).

\section{Statistical analysis}

Statistical analysis of the data was performed using STATA v14.0 (StataCorp, College Station, TX, USA) software. Population characteristics, H. pylori frequency, and the relationship between H. pylori and gastric symptoms were compared using Fisher's exact test or the $\mathrm{X}^{2}$ test when appropriate. Correlation between $H$. pylori detection methods was calculated using the Kappa index. Statistical significance was considered when $p<0.05$.

\section{Results}

A total of 171 children, 45\% (77/171) boys and 55\% (94/171) girls, participated in the study, with an average age of 8.9 and 8.5 years old, respectively (age range between 6 to 12 years) (Table 1). Most of the children $(91.8 \%, 157 / 171)$ were living in a rural community.

A child was considered to be $H$. pylori-positive when any of the samples gave positive results to bacterial DNA or antigens detection (either in one, two, or three samples). It is worth mentioning 
148 that some dental plaque and saliva samples were excluded because the sample or the purified

DNA were insufficient, and not all the participants provided a stool sample. The overall prevalence of $H$. pylori was $59.6 \%(102 / 171)$ (Table 2). Our results showed that the frequency of H. pylori was higher in girls, $38.6 \%(66 / 171)$ than in boys, $21 \%(36 / 171)$, and that there was no difference in prevalence among age groups (Table 1). Of the $102 \mathrm{H}$. pylori-positive cases, $64.7 \%$ (66) were girls. Overcrowding was not a risk factor for $H$. pylori infection in this population. An overcrowding condition was considered when three or more people slept in the same room.

\section{H. pylori frequency by sample type}

In order to determine the frequency of $H$. pylori, 111 samples of saliva, 121 of dental plaque, and 141 of feces were analyzed. The highest $H$. pylori frequency was found in stool samples $(50.4 \%)$ (Table 2). The prevalence of $H$. pylori in saliva and dental plaque was significantly higher in girls $(26.9 \%, p=0.002 ; 35.2 \%, p=0.038$, respectively) than in boys. In feces, no significant difference was found in $H$. pylori prevalence between both genders $(\mathrm{p}=0.786)$. A variable percentage of children were $H$. pylori-positive in one, two, or three samples (Fig. 3). 65.7\% $(67 / 102)$ of cases were positive in one sample, $22.5 \%(23 / 102)$ in two, and $3.9 \%(4 / 102)$ in all three samples.

\section{Concordance between detection methods}

The prevalence of $H$. pylori infection detected by conventional PCR in dental plaque samples was lower than that obtained by SAT, and no agreement was found between the results $(\kappa=-$ $0.1525)$. A poor agreement was found when the results obtained by conventional PCR of saliva samples and SAT were compared $(\kappa=0.09)$ (Table 3$)$.

\section{H. pylori and symptoms}

All the children that participated in this study were considered healthy, since they reported no disease. Nevertheless, we asked them if they had any gastric symptom (Table 4). The percentage of $H$. pylori-positive children with frequent belching $(16.7 \%)$ was significantly higher $(\mathrm{p}=0.035)$ than that of the H. pylori-negative (5.8\%). 29.4\% of the H. pylori-positive children referred suffering stomachache, however, there was no statistically significant difference with the $H$. pylori-negative children ( $\mathrm{p}=0.952$ ). Between $2.9 \%$ and $16.7 \%$ of the $H$. pylori-positive children showed some symptom related to gastric infection by this bacterium, however, the percentages were not significantly different from those found in $H$. pylori-negative children. None of these symptoms were related to $H$. pylori infection.

\section{Discussion}

H. pylori infection occurs at early ages in developing countries and can cause several pathological conditions like gastritis, peptic ulcer disease, iron deficiency anemia, and growth faltering (Rajindrajith et al., 2009). Therefore, assessing children in regions with high prevalence of $H$. pylori infection is important to prevent related complications (Ortiz-Princz et al., 2016). 
184 Reference methods for $H$. pylori diagnosis are culture and histology, both invasive methods 185 (Talebi Bezmin Abadi, 2018). However, in healthy or asymptomatic children, endoscopy is not 186 justified, and so non-invasive tests are recommended. In this work we used three methods to 187 determine $H$. pylori prevalence in apparently healthy Mexican children from the state of 188 Guerrero. We found an overall frequency of 59.6\%. This frequency is higher than those found in

189 190 191 children from Mexico City and Monterrey (35-38\%) in apparently healthy children (Duque et al., 2012; Mendoza et al., 2014; Valdez-Gonzalez et al., 2014; Mendoza-Cantu et al., 2017). This difference could be because the children that participated in this study are from a rural area, where the socioeconomic conditions are more precarious, besides the differences due to the geographical area and the methods used.

Contrary to previous reports that state that crowding is significantly associated with $H$. pylori infection, and that the frequency of infection increases with age (Torres et al., 1998; Galal et al., 2019), we found that $H$. pylori prevalence was very similar in all the age groups analyzed, and that crowding was not related to $H$. pylori frequency. On the other hand, gender was identified as a relevant characteristic for $H$. pylori acquisition, since most of the girls were $H$. pylori positive $(p=0.002)$. The reason for these findings is not known, and our results disagree with recent reports that have found no difference between genders, or male sex association with a higher $H$. pylori prevalence (Duque et al., 2012; Valdez-Gonzalez et al., 2014; Ibrahim et al., 2017; Mendoza-Cantu et al., 2017). The higher prevalence of $H$. pylori in girls (38.6\%) than in boys $(21 \%)$ is only in agreement with a previous report in Mexican population (Torres et al., 1998). This result was obtained by PCR of dental plaque (35.2\%), followed by PCR of saliva samples (26.9\%), while no difference between genders was found by SAT. It is proposed that the presence of $H$. pylori in the oral cavity is transitory and that it can be acquired by the oral-oral route. These results can be due to the fact that girls tend to be more affectionate and more likely to share food, candies, drinks, etc., and this contributes to a higher H. pylori presence in the oral cavity of girls than in boys.

In this work, H. pylori prevalence in dental plaque was $28.1 \%$, which is lower than that found by Valdez-Gonzalez et al., 2014 and Mendoza-Cantu et al., 2017 (35\% and 38\%, respectively). In both studies, $H$. pylori detection was done by qPCR, while we used conventional PCR. The discrepancies can be attributed to differences in the sensitivity of the method used, in the origin of the population and in the age group studied. However, our results are relevant in the context of children's oral health. In Mexican children, the prevalence of gingivitis associated or not with dental plaque varies from 14\% to $91.3 \%$ and varies between the children's geographical regions of origin and age (Taboada Aranza and Talavera Peña, 2011; Rocha Navarro et al., 2014). Although there are great controversies about the relationship between $H$. pylori infection with gingivitis and periodontal disease, there are data that strengthen the hypothesis that the bacterium is associated with these pathologies (Anand et al., 2014). In a study conducted by Flores-Treviño et al (2019) in Mexican adults with periodontitis, 60.5\% were $H$. pylori-positive. Together, these data suggest that $28.1 \%$ of asymptomatic children with $H$. pylori in their dental plaque, are at risk of gastric infection and/or of developing oral pathology associated with the bacteria. 
224 The stool antigen test detects $H$. pylori antigens in the infected subject, which disappear once the

225

226

227

228

229

230

231

232

233

234

235

236

237

238

239

240

241

242

243

244

245

246

247

248

249

250

251

252

253

254

255

256

257

258

259

260

bacteria are eradicated, so it is considered that this test provides evidence of an active infection (Ricci et al., 2007). Our results suggest that there is some factor that favors $H$. pylori permanence on the oral cavity of girls or that the bacterium is more frequently acquired by them, but once it gets to the stomach it can effectively colonize the mucous of both sexes. Nevertheless, previous reports using qPCR (Mendoza-Cantu et al., 2017) or culture-qPCR (Valdez-Gonzalez et al., 2014; Mendoza-Cantu et al., 2017) to detect $H$. pylori DNA in dental plaque samples, found no difference in the prevalence of infection between girls and boys. More work is needed in order to verify the reasons for these differences, keeping in mind that the differences in frequency of infection could be due to the sample site, the sampling method, the H. pylori detection method, and the differences in the number of subjects included in the studies. Also, socioeconomic conditions, children's age, as well as the geographical region from which they come, are factors that can influence too.

Regarding the methods used, PCR of saliva and dental plaque have a sensitivity and specificity of 95\% (Bermúdez Díaz et al., 2009), while the values for detection of antigens in feces are $>94 \%$ and $>99 \%$, respectively (Certest $H$. pylory Biotec, 2019). Despite having similar sensitivity values, a concordance analysis showed that there is poor to no agreement between the results from PCR and SAT. According to our results the antigen detection in feces is a better method for detection of $H$. pylori infected children (more sensitive), besides being faster and less expensive than molecular methods. In addition, the presence of $H$. pylori antigens in feces indicates an active gastrointestinal infection, while the presence of its DNA in oral cavity can be due to transient or dead bacteria. On the other hand, in children it is more feasible to obtain a stool sample than dental plaque and saliva samples with the required quality. However, a major disadvantage of SAT is that this method does not provide information about vacA genotype or $\operatorname{cag} A$ status of the bacterium, making it necessary to perform other methods.

H. pylori infection is mainly acquired during the first years of life, and the infected children show no symptoms (Talebi Bezmin Abadi, 2018). Even though the children that participated in this work were apparently healthy, we found that some of them had symptoms of gastritis, however none of these were related to $H$. pylori.

\section{Conclusions}

In conclusion, we found a high $H$. pylori prevalence among asymptomatic children from 6 to 12 years of age from Guerrero, Mexico, and the SAT method was more sensible to detect H. pylori infection than DNA detection from the bacterium in saliva or dental plaque.

\section{Acknowledgements}

We would like to thank students from groups 501 and 502 (generation 2017-2022) of periodontics clinic class of the Faculty of Dentistry of the Autonomous University of Guerrero, for helping in taking dental plaque samples. 
261

262

263

264

265

266

267

268

269

270

271

272

273

274

275

276

277

278

279

280

281

282

283

284

285

286

287

288

289

290

291

292

293

294

295

296

297

298

299

300

301

302

303

304

305

\section{References}

1. Al Sayed, A., P. S. Anand, K. P. Kamath, S. Patil, R. S. Preethanath and S. Anil (2014). "Oral Cavity as an Extragastric Reservoir of Helicobacter pylori." ISRN Gastroenterol 2014: 261369.

2. Anand, P. S., K. P. Kamath and S. Anil (2014). "Role of dental plaque, saliva and periodontal disease in Helicobacter pylori infection." World J Gastroenterol 20(19): 5639-5653.

3. Bermúdez Díaz, L., L. Ernesto Torres Domínguez and B. L. Rodríguez González (2009). "Métodos para la detección de la infección por Helicobacter pylori." Revista Cubana de Medicina 48: 0-0.

4. Bosques-Padilla, F. J., J. M. Remes-Troche, M. S. Gonzalez-Huezo, G. Perez-Perez, J. TorresLopez, J. M. Abdo-Francis, M. V. Bielsa-Fernandez, M. C. Camargo, F. EsquivelAyanegui, E. Garza-Gonzalez, A. I. Hernandez-Guerrero, R. Herrera-Goepfert, F. M. Huerta-Iga, Y. Leal-Herrera, A. Lopez-Colombo, N. X. Ortiz-Olvera, A. Riquelme-Perez, C. L. Sampieri, L. F. Uscanga-Dominguez and J. A. Velarde-Ruiz Velasco (2018). "The fourth Mexican consensus on Helicobacter pylori." Rev Gastroenterol Mex 83(3): 325341.

5. Campbell, D. I. and J. E. Thomas (2005). "Helicobacter pylori infection in paediatric practice." Archives of disease in childhood - Education \&amp; practice edition 90(2): ep25-ep30.

6. Certest H. pylory Biotec, S. L. (2019). "Helicobacter pylori detection kit.".

7. Chang, Y. H., L. Wang, M. S. Lee, C. W. Cheng, C. Y. Wu and M. Y. Shiau (2006). "Genotypic characterization of Helicobacter pylori cagA and vacA from biopsy specimens of patients with gastroduodenal diseases." Mt Sinai J Med 73(3): 622-626.

8. Duque, X., J. Vilchis, R. Mera, B. Trejo-Valdivia, K. J. Goodman, M. E. Mendoza, F. Navarro, V. Roque, S. Moran, J. Torres and P. Correa (2012). "Natural history of Helicobacter pylori infection in Mexican schoolchildren: incidence and spontaneous clearance." $\underline{\mathrm{J} \text { Pediatr }}$ Gastroenterol Nutr 55(2): 209-216.

9. Flores-Trevino, C. E., V. H. Urrutia-Baca, R. Gomez-Flores, M. A. De La Garza-Ramos, M. M. Sanchez-Chaparro and M. A. Garza-Elizondo (2019). "Molecular detection of Helicobacter pylori based on the presence of cagA and vacA virulence genes in dental plaque from patients with periodontitis." J Dent Sci 14(2): 163-170.

10. Galal, Y. S., C. M. Ghobrial, J. R. Labib and M. E. Abou-Zekri (2019). "Helicobacter pylori among symptomatic Egyptian children: prevalence, risk factors, and effect on growth." Journal of the Egyptian Public Health Association 94(1): 17.

11. Guarner, J., N. Kalach, Y. Elitsur and S. Koletzko (2010). "Helicobacter pylori diagnostic tests in children: review of the literature from 1999 to 2009." Eur J Pediatr 169(1): 15-25.

12. Hasosah, M., M. Satti, A. Shehzad, A. Alsahafi, G. Sukkar, A. Alzaben, A. Sunaid, A. Ahmed, S. AlThubiti, A. Mufti and K. Jacobson (2015). "Prevalence and risk factors of Helicobacter pylori infection in Saudi children: a three-year prospective controlled study." Helicobacter 20(1): 56-63.

13. Ibrahim, A., S. Morais, A. Ferro, N. Lunet and B. Peleteiro (2017). "Sex-differences in the prevalence of Helicobacter pylori infection in pediatric and adult populations: Systematic review and meta-analysis of 244 studies." Dig Liver Dis 49(7): 742-749.

14. Jones, N. L., S. Koletzko, K. Goodman, P. Bontems, S. Cadranel, T. Casswall, S. Czinn, B. D. Gold, J. Guarner, Y. Elitsur, M. Homan, N. Kalach, M. Kori, A. Madrazo, F. Megraud, A. Papadopoulou and M. Rowland (2017). "Joint ESPGHAN/NASPGHAN Guidelines for the 
Management of Helicobacter pylori in Children and Adolescents (Update 2016)." J Pediatr Gastroenterol Nutr 64(6): 991-1003.

15. Khalifa, M. M., R. R. Sharaf and R. K. Aziz (2010). "Helicobacter pylori: a poor man's gut pathogen?" Gut Pathog 2(1): 2.

16. Malaty, H. M., A. El-Kasabany, D. Y. Graham, C. C. Miller, S. G. Reddy, S. R. Srinivasan, Y. Yamaoka and G. S. Berenson (2002). "Age at acquisition of Helicobacter pylori infection: a follow-up study from infancy to adulthood." Lancet 359(9310): 931-935.

17. Mendoza-Cantu, A., V. H. Urrutia-Baca, C. S. Urbina-Rios, M. A. De la Garza-Ramos, M. E. Garcia-Martinez and H. H. H. Torre-Martinez (2017). "Prevalence of Helicobacter pylori vacA Genotypes and cagA Gene in Dental Plaque of Asymptomatic Mexican Children." Biomed Res Int 2017: 4923640.

18. Mendoza, E., M. Camorlinga-Ponce, G. Perez-Perez, R. Mera, J. Vilchis, S. Moran, O. Rivera, R. Coria, J. Torres, P. Correa and X. Duque (2014). "Present and past Helicobacter pylori infection in Mexican school children." Helicobacter 19(1): 55-64.

19. Ortiz-Princz, D., G. Daoud, A. Salgado-Sabel and M. E. Cavazza (2016). "Helicobacter pylori infection in children: should it be carefully assessed?" Eur Rev Med Pharmacol Sci 20(9): 1798-1813.

20. Peek, R. M., Jr. and J. E. Crabtree (2006). "Helicobacter infection and gastric neoplasia." J Pathol 208(2): 233-248.

21. Rajindrajith, S., N. M. Devanarayana and H. J. de Silva (2009). "Helicobacter pylori infection in children." Saudi J Gastroenterol 15(2): 86-94.

22. Ricci, C., J. Holton and D. Vaira (2007). "Diagnosis of Helicobacter pylori: invasive and noninvasive tests." Best Pract Res Clin Gastroenterol 21(2): 299-313.

23. Rocha Navarro, M. L., S. Serrano Reyes, M. E. Fajardo Araujo and V. H. G. Servín Zavala (2014). "Prevalencia y grado de gingivitis asociada a placa dentobacteriana en niños." Nova scientia 6: 190-218.

24. Roman-Roman, A., D. N. Martinez-Carrillo, J. Atrisco-Morales, J. C. Azucar-Heziquio, A. S. Cuevas-Caballero, C. A. Castanon-Sanchez, R. Reyes-Rios, R. Betancourt-Linares, S. Reyes-Navarrete, I. Cruz-Del Carmen, M. Camorlinga-Ponce, E. M. Cortes-Malagon and G. Fernandez-Tilapa (2017). "Helicobacter pylori vacA s1m1 genotype but not cagA or babA2 increase the risk of ulcer and gastric cancer in patients from Southern Mexico." Gut Pathog 9: 18.

25. Taboada Aranza, O. and I. Talavera Peña (2011). "Prevalencia de gingivitis en una población preescolar del oriente de la Ciudad de México." Boletín médico del Hospital Infantil de México 68: 21-25.

26. Talebi Bezmin Abadi, A. (2018). "Diagnosis of Helicobacter pylori Using Invasive and Noninvasive Approaches." J Pathog 2018: 9064952.

27. Torres, J., Y. Leal-Herrera, G. Perez-Perez, A. Gomez, M. Camorlinga-Ponce, R. CedilloRivera, R. Tapia-Conyer and O. Munoz (1998). "A community-based seroepidemiologic study of Helicobacter pylori infection in Mexico." J Infect Dis 178(4): 1089-1094.

28. Valdez-Gonzalez, J., P. Mares-Moreno, M. Kowolik, J. Vargas-Villarreal, F. GonzalezSalazar and M. A. De la Garza-Ramos (2014). "Detection of Helicobacter pylori in dental plaque of mexican children by real-time PCR." Health 6: 231-235. 


\section{Figure 1}

Representative results of $H$. pylori detection in oral samples.

H. pylori DNA (Hp 16S) detection in (A) dental plaque and (B) saliva samples of asymptomatic children 6 to 12 years old. Lanes: MW- molecular weight marker; -C - negative control; +C - positive control; DP-127 and DP-128- H. pylori positive samples; DP-129- H. pylori negative sample; S-019- H. pylori positive sample; S-001, S-072, and S-055- H. pylori negative samples. IL-1 $\beta$ product was amplified as a DNA integrity control. DP- dental plaque, S- saliva. 

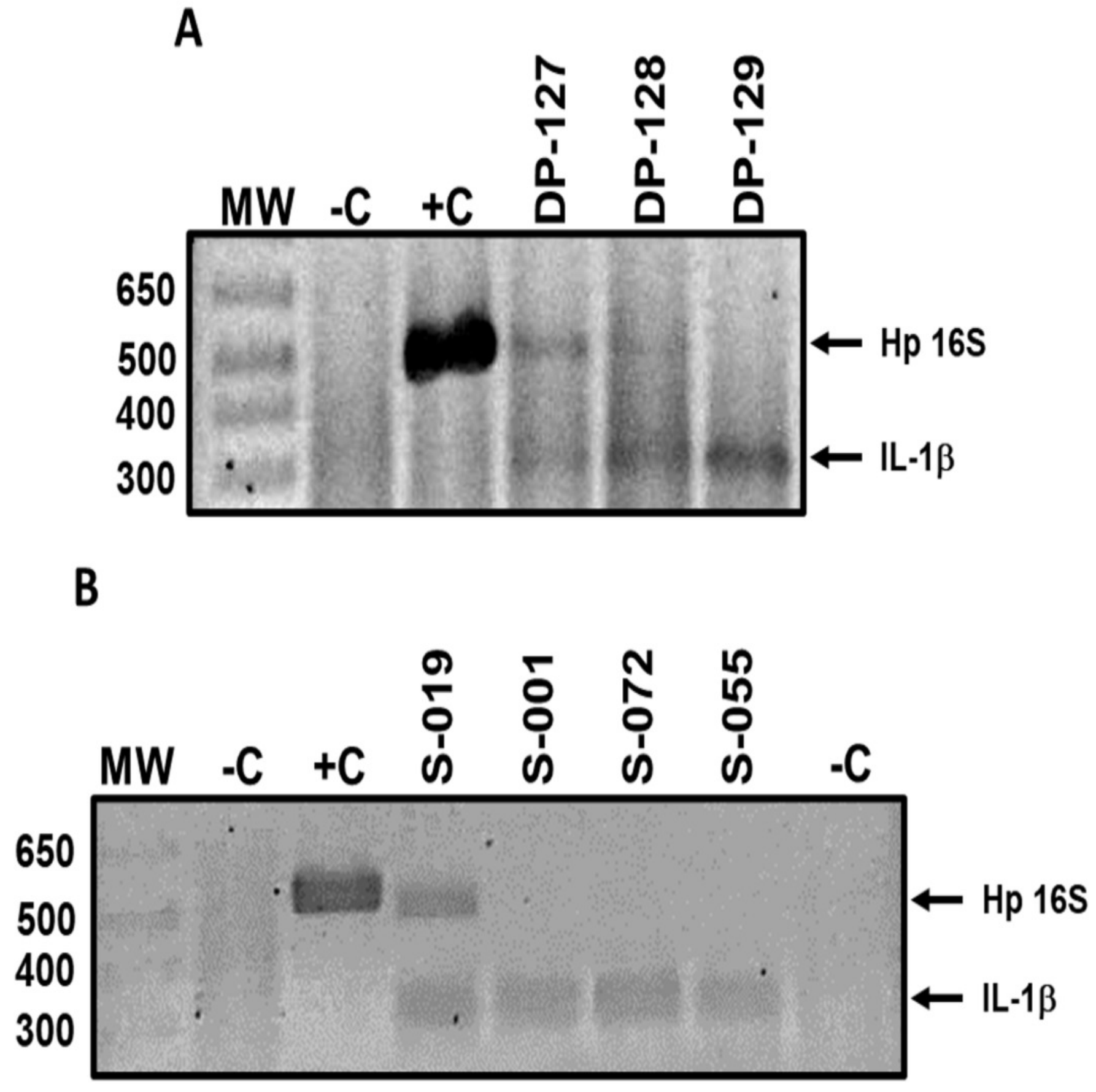


\section{Figure 2}

Representative results of $H$. pylori detection in feces.

Negative (UAO-011 y UAO-010) and positive (UAO-008 y UAO-003) samples are shown. The green band is the control, and the red line indicates $H$. pylori presence.

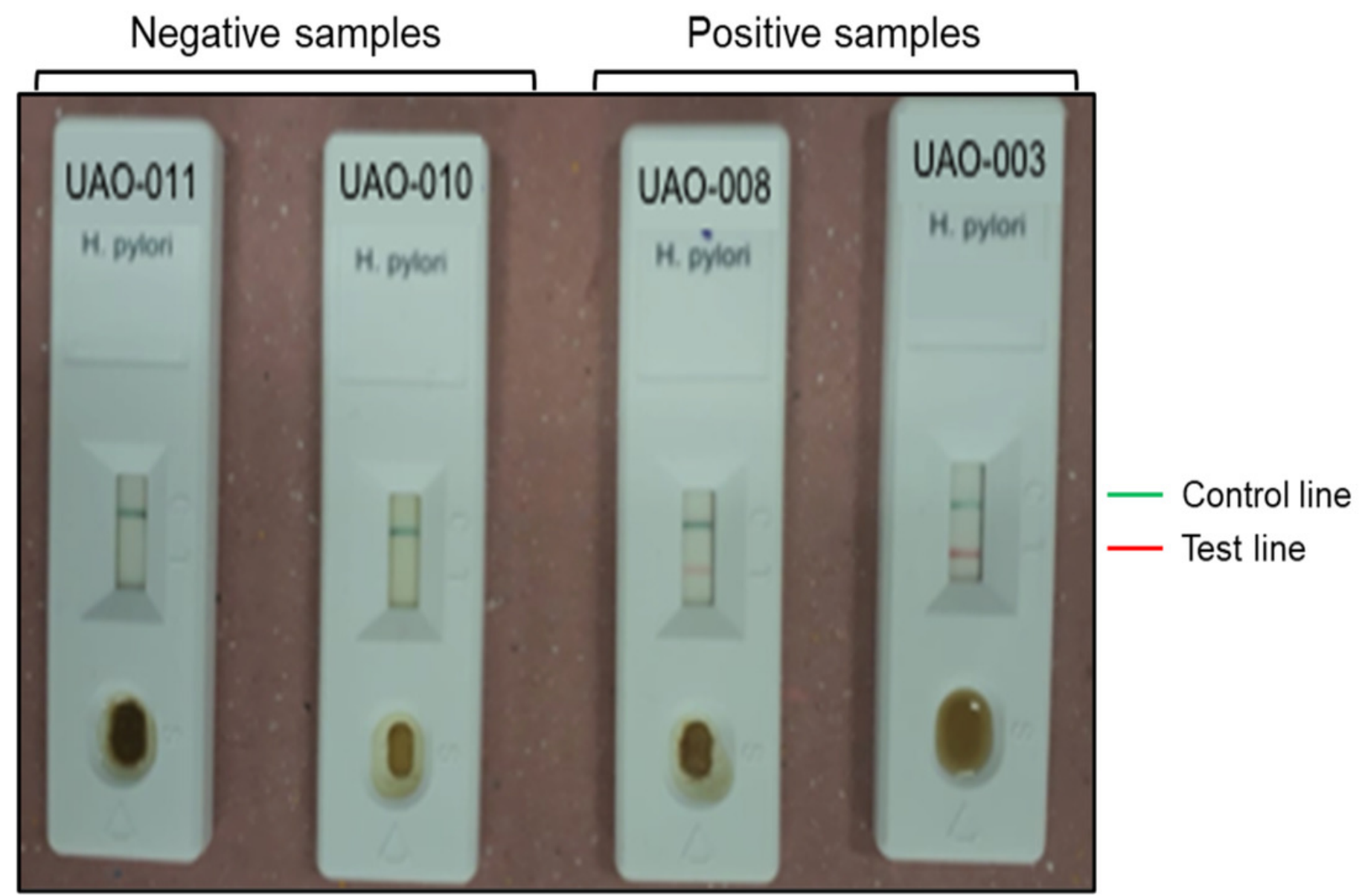


Figure 3

Distribution of positive results.

Venn diagram showing the number of $H$. pylori positive children according to sample type.

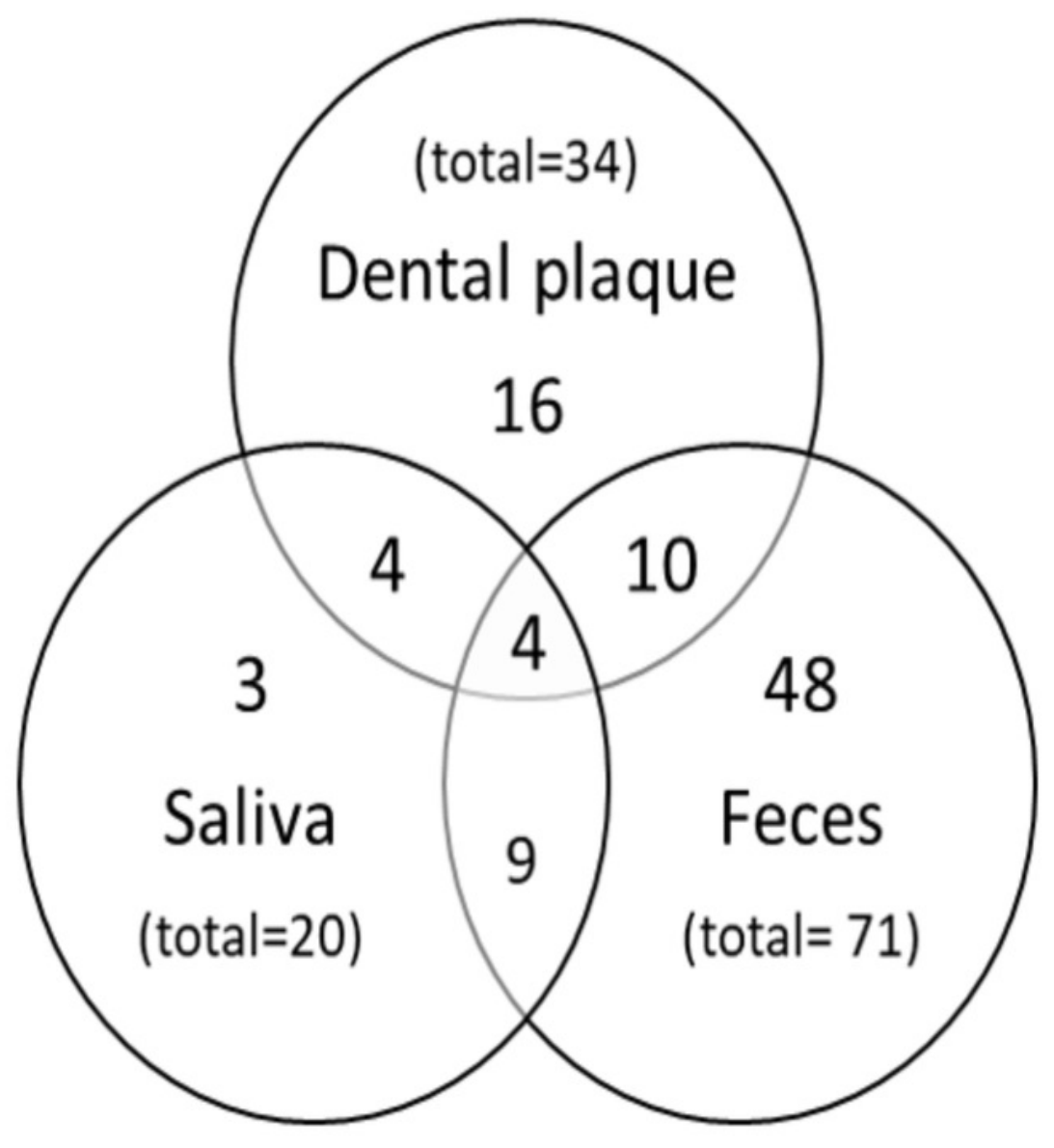




\section{Table 1 (on next page)}

Sociodemographic characteristics and $H$. pylori frequency in Mexican children aged 6 to 12 without gastric disease

${ }^{\Omega} X^{2}$ test. 
1 Table 1. Sociodemographic characteristics and $H$. pylori frequency in Mexican children aged 6 to 12 without 2 gastric disease.

\begin{tabular}{|c|c|c|c|}
\hline Characteristics & $\begin{array}{c}\text { H. pylori negative } \\
\mathrm{n}=69\end{array}$ & $\begin{array}{c}\text { H. pylori positive } \\
\mathrm{n}=102\end{array}$ & $p$ value ${ }^{\Omega}$ \\
\hline $\begin{array}{c}\text { Sex, } \mathbf{n}(\%) \\
\text { Masculine } \\
\text { Feminine }\end{array}$ & $\begin{array}{l}41(59.4) \\
28(40.6)\end{array}$ & $\begin{array}{l}36(35.3) \\
66(64.7)\end{array}$ & 0.002 \\
\hline $\begin{array}{l}\text { Age, } \mathbf{n}(\%) \\
6 \text { - } 7 \text { years } \\
8 \text { - } 9 \text { years } \\
10 \text { - } 11 \text { years } \\
12 \text { years }\end{array}$ & $\begin{array}{l}12(17.4) \\
34(49.3) \\
17(24.6) \\
6(8.7)\end{array}$ & $\begin{array}{c}34(33.3) \\
38(37.3) \\
22(21.6) \\
8(7.8)\end{array}$ & 0.138 \\
\hline $\begin{array}{l}\text { Overcrowding, } \mathbf{n}(\%) \\
\text { No ( } \leq 2 \text { people/room) } \\
\text { Si (>2 people/room) }\end{array}$ & $\begin{array}{l}27(39.1) \\
42(60.9)\end{array}$ & $\begin{array}{l}54(52.9) \\
48(47.1)\end{array}$ & 0.076 \\
\hline
\end{tabular}




\title{
Table 2 (on next page)
}

H. pylori frequency in asymptomatic children by sample type

\author{
${ }^{\circledR}$ Fisher's exact test; ${ }^{\Omega} \mathrm{X}^{2}$ test
}


1 Table 2. H. pylori frequency in asymptomatic children by sample type.

\begin{tabular}{|c|c|c|c|c|}
\hline H. pylori presence & Boys & Girls & Total & $p$ value \\
\hline Saliva, n (\%) & & & & $0.002^{\&}$ \\
\hline Negative & $42(95.4)$ & $49(73.1)$ & $91(82)$ & \\
\hline Positive & $2(5.6)$ & 18 (26.9) & $20(18)$ & \\
\hline Total & $44(100)$ & $67(100)$ & $111(100)$ & \\
\hline Dental plaque, n (\%) & & & & $0.038^{\Omega}$ \\
\hline Negative & $41(82)$ & $46(64.8)$ & 87 (71.9) & \\
\hline Positive & $9(18)$ & $25(35.2)$ & $34(28.1)$ & \\
\hline Total & $50(100)$ & $71(100)$ & $121(100)$ & \\
\hline Stool, n (\%) & & & & $0.786^{\Omega}$ \\
\hline Negative & $29(48.3)$ & $41(46.1)$ & $70(49.6)$ & \\
\hline \multirow[t]{2}{*}{ Positive } & $31(51.7)$ & $40(53.9)$ & $71(50.4)$ & \\
\hline & $60(100)$ & $81(100)$ & $141(100)$ & \\
\hline H. pylori status, n (\%) & & & & $0.002^{\Omega}$ \\
\hline Negative & $41(53.3)$ & $28(29.8)$ & $69(40.4)$ & \\
\hline Positive & $36(46.8)$ & $66(70.2)$ & $102(59.6)$ & \\
\hline Total & 77 (100) & $94(100)$ & $171(100)$ & \\
\hline
\end{tabular}

2 \& Fisher's exact test; ${ }^{\Omega} \mathrm{X}^{2}$ test 


\section{Table 3(on next page)}

Concordance among $H$. pylori DNA detection in saliva and dental plaque samples and SAT from children between 6 and 12 years old without gastric disease

${ }^{\Omega} X^{2}$ test. 
1 Table 3. Concordance among $H$. pylori DNA detection in saliva and dental plaque samples and SAT from 2 children between 6 and 12 years old without gastric disease

\begin{tabular}{|c|c|c|c|}
\hline \multirow{2}{*}{$\begin{array}{c}\text { Dental plaque } \\
\text { (H. pylori DNA) } \\
\text { n (\%) }\end{array}$} & \multicolumn{2}{|c|}{ Antigens in feces $\mathbf{n}(\%)$} & \multirow[b]{2}{*}{$p$ value $\Omega$} \\
\hline & Negative & Positive & \\
\hline Negative & $27(58.7)$ & $41(74.5)$ & \multirow{3}{*}{0.091} \\
\hline Positive & $19(41.3)$ & $14(25.5)$ & \\
\hline Total & $46(100)$ & $55(100)$ & \\
\hline \multicolumn{3}{|c|}{ Kappa index $=-0.1525$} & 0.9546 \\
\hline $\begin{array}{c}\text { Saliva } \\
\text { (H. pylori DNA) } \\
\mathrm{n}(\%)\end{array}$ & Negative & Positive & \\
\hline Negative & $42(85.7)$ & $42(76.4)$ & \multirow{3}{*}{0.227} \\
\hline Positive & $7(14.3)$ & $13(23.6)$ & \\
\hline Total & $49(100)$ & $55(100)$ & \\
\hline \multicolumn{3}{|c|}{ Kappa index $=0.09$} & 0.1136 \\
\hline
\end{tabular}

$\bar{\Omega} X^{2}$ test. 


\section{Table 4(on next page)}

Relationship between $H$. pylori and gastritis symptoms

${ }^{\circledR}$ Fisher's exact test; ${ }^{\circledR} \mathrm{X}^{2}$ test. 
1 Table 4. Relationship between $H$. pylori and gastritis symptoms

\begin{tabular}{|c|c|c|c|}
\hline Symptom & H. pylori negative & H. pylori positive & $p$ value \\
\hline \multicolumn{4}{|l|}{ Vomit, n (\%) } \\
\hline No & $65(94.2)$ & $97(95.1)$ & $1.000^{\&}$ \\
\hline Yes & $4(5.8)$ & $5(4.9)$ & \\
\hline \multicolumn{4}{|l|}{ Nausea, n (\%) } \\
\hline No & $63(91.3)$ & $99(97.1)$ & $0.160^{\&}$ \\
\hline Yes & $6(8.7)$ & $3(2.9)$ & \\
\hline \multicolumn{4}{|c|}{ Frequent belching, n (\%) } \\
\hline No & $65(94.2)$ & $85(83.3)$ & $0.035^{\&}$ \\
\hline Yes & $4(5.8)$ & $17(16.7)$ & \\
\hline \multicolumn{4}{|l|}{ Stomachache, n (\%) } \\
\hline No & $49(71)$ & $72(70.6)$ & $0.952^{\Omega}$ \\
\hline Yes & $20(29)$ & $30(29.4)$ & \\
\hline \multicolumn{4}{|l|}{ Heartburn, n (\%) } \\
\hline No & $66(95.7)$ & $95(93.1)$ & $0.742^{\&}$ \\
\hline Yes & $3(4.3)$ & $7(6.9)$ & \\
\hline \multicolumn{4}{|l|}{ Diarrhea, n (\%) } \\
\hline No & $63(91.3)$ & $98(96.1)$ & $0.205^{\&}$ \\
\hline Yes & $6(8.7)$ & $4(3.9)$ & \\
\hline
\end{tabular}

\& Fisher's exact test; ${ }^{\Omega} \mathrm{X}^{2}$ test. 